\title{
Deformation processes in open drainages
}

\author{
Dilbar Abduraimova, Zaytuna Ibragimova, Makhsud Otakhonov ${ }^{*}$, and Djamila Khusanova \\ Tashkent Institute of Irrigation and Agricultural Mechanization Engineers, Tashkent, Uzbekistan
}

\begin{abstract}
The quality and quantity of agricultural products depend on land reclamation. Collector-drainage systems are used to improve the reclamation state of irrigated areas. The article discusses the stability of slopes of open collector-drainage networks in the irrigated lands of the Hungry Steppe. Discussed problems create during construction and providing productivity of drainages system in irrigation fields. The causes of the deformation process are discussed. The deformation process occurring as a result of landslides of the banks of open collectors is estimated. Recommendations for determining the stability of the banks of an open collector are based on the definition of a model of circular cylindrical sliding surfaces. Used statistic law of mechanics in calculation work based on the model of the ground movement around a cylindrical surface. During calculations, the main attention is given to the weight force, hydrodynamic force, and bite force of the ground. Stability coefficient calculated according to keeping moment (M1) moving moment (M2). In determining the stability of the soil, the main factor of the coupling of the adhesion between the soil particles is substantiated. The suffusion process occurring as a result of moistening and salinization of the soil of the shores of an open reservoir is estimated and analyzed, decreasing of stagnation coefficient in a result of ground absorption process. Analyzing soil samples of various salinities under laboratory conditions, soil adhesion was evaluated. Based on the studies, recommendations are given for the restoration of the shores of open drainages. The given recommendations are based on increasing the drainage's resilience and preventing deformation processes from constructing the drainage in slopes.
\end{abstract}

\section{Introduction}

Collector-drainage systems (CDS) play an important role in improving the reclamation state of irrigated lands. The main part of the irrigated lands of the Hungry Steppe is made up of sowing areas of the Syr Darya region. To provide water for the irrigated lands of the Syr Darya region in 1896, the Dustlik canal was built. Subsequently, in 1926, $180 \mathrm{~km}$ of canals and canals were built, irrigated areas reached 53 thousand hectares. As a result of the intensive development of the steppes in 1956, irrigated land areas reached 280 thousand hectares, and agricultural products were grown. By constructing in 1960 a canal in the southern Hungry Steppe and Boevut, the Farhad reservoir, the tasks of irrigation of the

*Corresponding author: maksud.otakhonov@bk.ru 
southern part of the Hungry Steppe were solved[1,2,3]. The imperfect work of the CDS system led to an increase in the groundwater table, salinization, and worsening of the land reclamation state. The quality and quantity of agricultural products declined. To improve the reclamation state of the sowing areas, intensive construction of KDS began. In the beginning, drainage systems Shuruzak, Boevut, and Ettisay were built. Then, the drainage systems of Sardoba and Vostochny were built. Built-in 1958, the Central Hunger-Steppe collector at a length of $90 \mathrm{~km}$ began to serve for the removal of saline water from the Boevut and Ettisay water supply networks[4,5,6]. To ensure the intensive operation of drainage systems in the Syr Darya region, they are widely conducting treatment works. However, as result of salinization of the irrigated areas, it has affected the change in the soil composition of open collectors.

In the republic, in cases of irrigated land, there are very often cases of landslides of soils on the banks of constructed open collectors. There are deformation processes associated with expanding reservoir beds, raising the bottom, changes in design dimensions. All this led to a decrease in the efficiency of the CDS, the result of which is the rise of the underground groundwater horizon and cases of salinization. This condition can be found in almost all regions of the republic. To improve the reclamation state of the land, reconstruction of the CDS is required. The reconstruction of open collectors requires a lot of money. Since, when restoring the coast, the importation of many soils and, to the extent necessary, compaction is required. But, sometimes, due to the increased degree of soil salinity on the restored shores, landslides are again observed[7,8]. This requires additional costs.

\section{Methods}

Natural soils, in many cases, have an internal force of friction, as well as the strength of the relationship between particles. The method of circular cylindrical sliding surfaces makes it possible to assess the stability of a slope consisting of various soils[9,10]. In this method, the slip of the slope is accepted, based on numerous experiments, occurs as if on a roundcylindrical surface. And the position of the center of the circle is determined by calculations. Consider the slip of a slope consisting of an ABD prism. Imagine that the prism of the $\mathrm{ABD}$ slides along the arc of the $\mathrm{AB}$ of a circular cylinder, and its center is located at point $\mathrm{O}$.

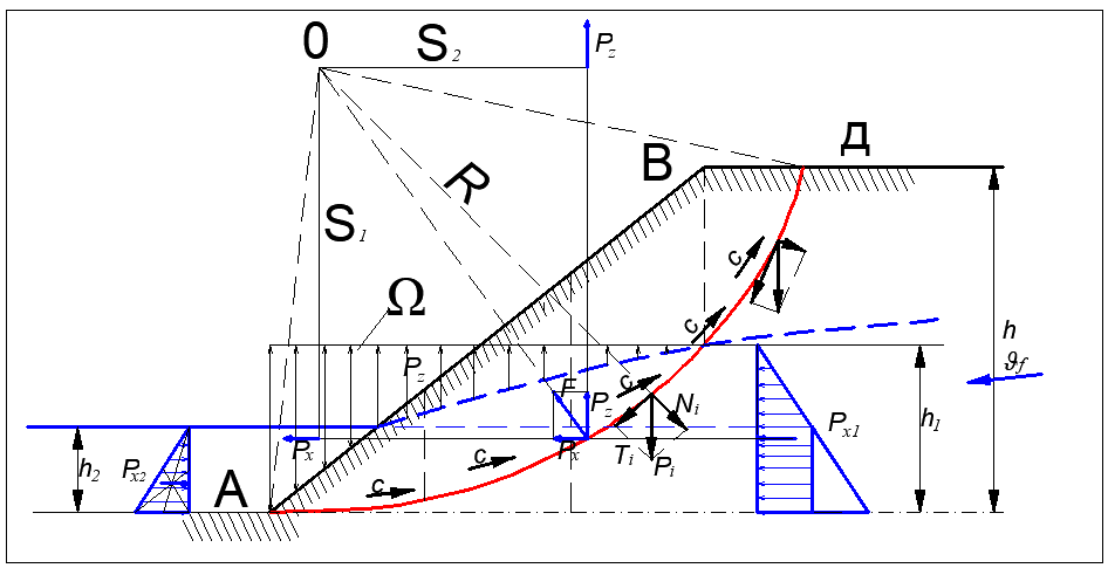

Fig. 1. Scheme of circular cylindrical sliding surfaces of the soil. 
In this case, the $\mathrm{ABD}$ is called the slip prism, and the $\mathrm{AD}$ curve is the slip area. Let $\mathrm{R}$ denote the radius of this circle, divide the prism of the ABD in the vertical direction into several parts. We do not consider the vertical forces arising within each part with the neighboring one (these forces are equal and arise in the opposite direction, respectively. We take one $\mathrm{i}$-th part from these parts. Let its weight $\mathrm{P}_{\mathrm{i}}$ be in the center along the arc. Divide the force $\mathrm{P}_{\mathrm{i}}$ by $\mathrm{N}_{\mathrm{i}}$-on normal and $\mathrm{T}_{\mathrm{i}}$-tangential force. Let the ABD slip prism be in the state of boundary stresses[12,13,14]. Therefore, taking the moments of all acting forces concerning point $\mathrm{O}$ and taking it equal to zero, we arrive at the equilibrium condition or

$$
\sum M=0
$$

We consider $\mathrm{L}$ as the length of the force of the relationship between the particles, distributed along the arc of AD.

$$
\sum M_{0}=\sum_{i=1}^{n} T_{i} \cdot R-\sum_{i=1}^{n} N_{i} \cdot \operatorname{tg} \varphi \cdot R-c \cdot L \cdot R+P_{x} \cdot S_{1}-P_{y} \cdot S_{2}=0
$$

there: $\mathrm{T}$ and $\mathrm{N}$ are components $(\mathrm{P})$ of the weight of the soil, $\mathrm{R}$ is radius of the arc, $\mathrm{L}$ is length of the arc, $\phi$ is angle of internal friction, $\mathrm{c}$ is cohesion of the soil, $\mathrm{F}$ is force hydrostatic pressure.

$$
\begin{gathered}
T_{i}=P_{i} \sin \alpha_{i} ; N_{i}=P_{i} \cos \alpha_{i} ; \operatorname{tg} \varphi=f ; F=\sqrt{P_{x}^{2}+P_{z}^{2}} ; P_{x}=P_{x 1}-P_{x 2} ; \\
P_{x 1}=\frac{\gamma \cdot h_{1}^{2}}{2} ; P_{x 2}=\frac{\gamma \cdot h_{2}^{2}}{2} ; P_{z}=\Omega \cdot \gamma_{\theta} .
\end{gathered}
$$

Expression (1) is reduced to $\mathrm{R}$

$$
\sum_{i=1}^{n} T_{i}-\sum_{i=1}^{n} N_{i} \cdot \operatorname{tg} \varphi-c \cdot L+P_{x} \cdot S_{1}-P_{y} \cdot S_{2}=0
$$

The ratio of the holding moment $\left(\mathrm{M}_{1}\right)$ to the moving one is the stability coefficient $\left(\mathrm{M}_{2}\right)$

$$
\eta=\frac{M_{1}}{M_{2}}=\frac{\left(\sum_{i=1}^{n} N_{i} \cdot \operatorname{tg} \varphi+c \cdot L\right) R+P_{y} \cdot S_{2}}{\sum T_{i} \cdot R+P_{x} \cdot S_{1}}
$$

The calculation of the stability coefficient does not end the calculation work. Because the center of the slip of the arc is chosen arbitrarily, therefore, it is necessary to determine the most dangerous position of the center of the slip area. For this, it is necessary to determine the minimum value of the stability coefficient for various positions of point $O$. 


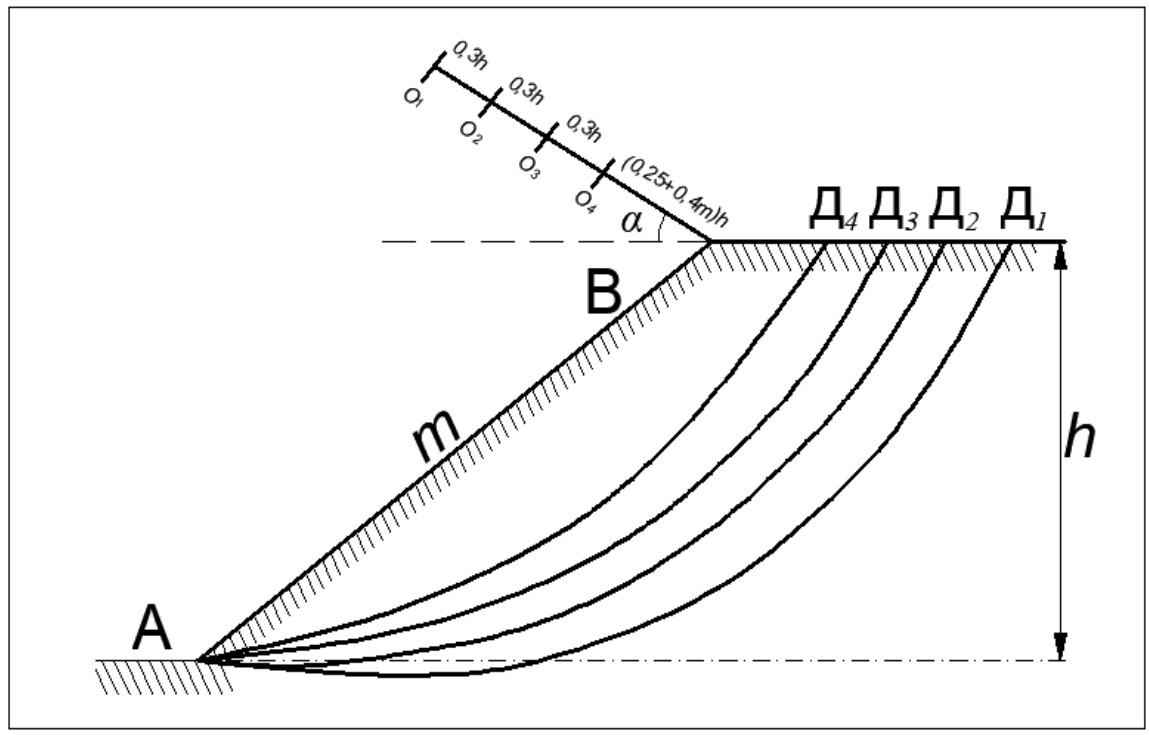

Fig. 2. Scheme of determining stability.

To facilitate the calculation work from the upper crest of the slope of point B relative to the horizon, a beam is directed at an angle $\alpha[15,16]$. Looking at the points O1, O2, O3, etc., located in it as the center of a circle according to the stability condition, the required strength of the interconnection of particles is determined by equation (1).

$$
c=\frac{\sum T_{i}-\sum_{i=1}^{n} N_{i} \cdot \operatorname{tg} \varphi+P_{x} \cdot S_{1}-P_{y} \cdot S_{2}}{L} .
$$

Then, from all possible centers of the circle, the largest required force of the interconnection of particles is determined. Looking at this point as the most dangerous center, the stability coefficient is determined by expression (2). If $\eta>{ }_{-} 1,1 \ldots 1,5$, the slope stability is ensured $[17,18]$.

If we analyze the above equation 2, we see that the stability of the slope in the drainage is associated with soil adhesion.

\section{Results and Discussion}

The channel of open drainages mainly consists of bound soils, the number of instant salts in the water increases in their composition. They cement the rock in a dry state and at the same time weaken it when moistened. This condition leads to swelling, moisture, and diffusion dissolution. As a result of water absorption in dry saline soil, salt dissolves as mechanical powder. One part of the saline solution is absorbed into the soil colloids. Another part replenishes the micro-hollows of the microaggregates. The rest, under the influence of the water flow, is removed from the soil. In this case, the soil strength concerning erosion decreases[19].

According to the composition of soluble salts in the soil, they can be divided into the following groups:

- $\quad$ slightly soluble (perchloric, salty with sulfur, sodium carbonate, and potassium salt); 
- $\quad$ sparingly soluble (calcium sulfate);

- $\quad$ sparingly soluble (calcium and magnesium carbonates).

Suffusion is a change in the physical and mechanical conditions of the soil under the influence of a stream of water. Salt suffusion leads to the destruction of the strength of the soil structure, i.e., leads to the release and dissolution of salts from the soil layer. In some cases, it is considered a cause of erosion.

The amount of salts in the soil is of primary importance in salt suffusion. A small number of them in the soil does not lead to dangerous suffusion deformations. A large amount in the soil under the influence of the flow leads to a change in the properties of the soil. This, from the point of view of the development of mechanical suffusion, will be dangerous. When soil is enriched with water, capillary forces disappear. The molecular force of attraction is reduced, and the properties of the addition of organic substances of salts and clay minerals are also reduced. So, with increasing soil moisture, its relationship decreases. As a result of a decrease in the relationship between soil moisture, the resistance of saline soils to hydrodynamic stress decreases. At the beginning of the dissolution of salts, a condition appears for the onset of mechanical suffusion [20].

To study the nature of saline-bound soils, samples were taken from the banks of open drainages. Of the samples taken in laboratory conditions, 4 different samples were prepared according to the degree of salinity, and experiments were carried out. According to the results of the experiments, the adhesion force and the angles of internal friction in salinebound soils were determined.

Table 1.Mechanical properties of saline soils.

\begin{tabular}{|c|c|}
\hline Ground sample & Bearing force $\mathrm{c}, \mathrm{kg} / \mathrm{cm} 2$ \\
\hline Non-saline ground & 0.35 \\
\hline Poor saline ground & 0.13 \\
\hline The average saline ground & 0.03 \\
\hline Highly saline ground & 0.017 \\
\hline
\end{tabular}

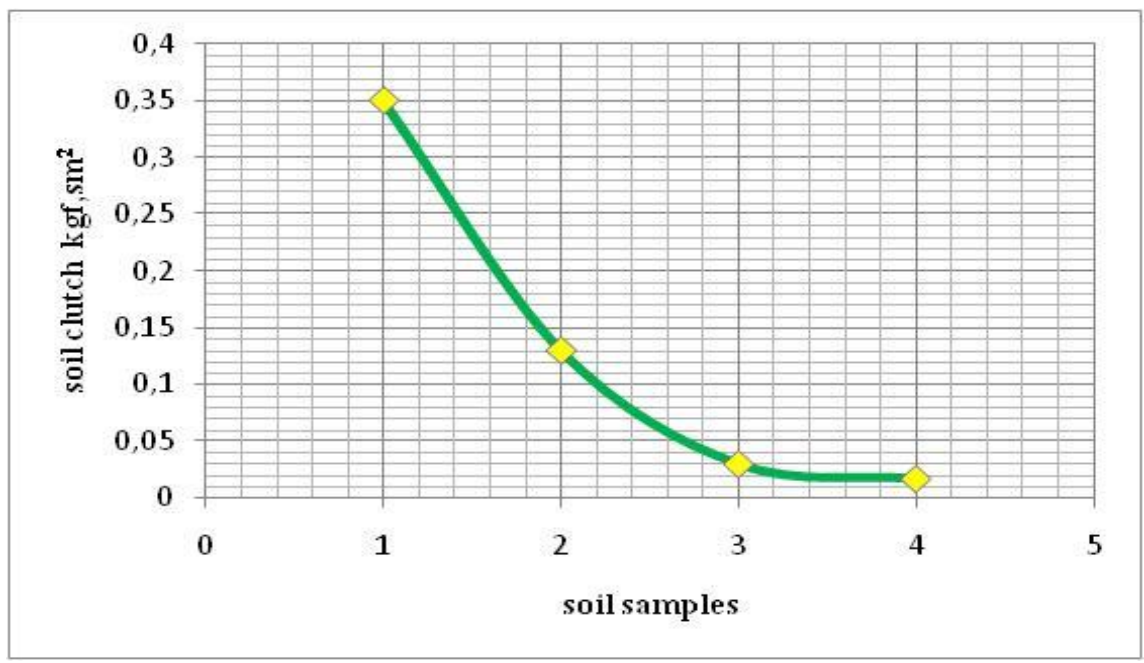

Fig. 3. Mechanical properties of saline soils

The analysis shows that the increasing salt content of the soil contributes to a decrease in the slope of the soil bed of channels. As a result, the banks of the collectors face to water erosion and moves to the center of the collector. 
We must justify the hydraulic parameters for the planning of open drainages, taking into account soil salinity. As a result, we will be able to prevent coastal collapse. The slope coefficient values in QM and Q are calculated only for nonsaline soils. Based on the above equations and samples analysis, the slope coefficient was calculated, taking into account the depth value for saline soils (Figure 4).



Fig. 4. The slope coefficient of the ground.

The slope coefficient proposed in $\mathrm{m}_{1}-\mathrm{QM}$ and $\mathrm{Q}$, in $\mathrm{m}_{2}$-saline granules.

The given graphic is the slope of the saline soils and is used for designing and constructing open drainages. As a result, the open drainages are prevented from deformation processes.

\section{Conclusions}

Determined the cause of the deformation processes as a result of erosion of the drainage bed shoreline. Based on the findings, one can summarize the following conclusions and recommendations for preventing deformation in open collectors.

In calculating the stability of the open drainages of the constructed openings, only calculations were performed taking into account the ground weight, internal friction, and bending forces. The effect of underground water is not taken into account. It is recommended that calculations be carried out, taking into account the force generated by groundwater impact.

During the planning of open collectors, there were not taken into account when soil salinity is taken into account. According to laboratory analysis and experiments, increased salinity leads to the occurrence of suction processes and reduced soil bending strength. As a result, the soil's stagnation decreases, and the deformation process occurs at the bottom of the ditch.

When planning open drainages and rebuilding the shoreline, samples from the granite should be collected and analyzed in the laboratory to determine salinity. Results allow us to predict soil stability.

Considering the problems mentioned above, a special slope coefficient was determined and recommended for practice when designing and constructing openings. The advantage 
of the proposed slope coefficient is that salinity results from salinity and underground ground water resistance. As a result, the deformation that occurs in the open ditch is prevented.

\section{References}

1. A. Arifjanov, M. Otaxonov, L. Samiev, and S. Akmalov, "Hydraulic calculation of horizontal open drainages," E3S Web Conf., vol. 97, (2019), doi: 10.1051/e3sconf/20199705039.

2. ] Arifjanov, A., Samiev, L., Apakhodjaeva, T., Akmalov, S. Distribution of river sediment in channels. (2019) IOP Conference Series: Earth and Environmental Science, 403 (1). DOI: 10.1088/1755-1315/403/1/012153

3. Arifzhanov, A.M. Method for calculation of the distribution of drift particles in variable section beds (VSB) Gidrotekhnicheskoe Stroitel'stvo, (2), pp. 44-45. (2004)

4. Arifzhanov, A.M. Distribution of Suspended Sediment Particles in a Steady-State Flow. (2001) Water Resources, 28 (2), pp. 164-166. DOI: 10.1023/A:1010375500148

5. Rakhimov, K., Ahmedkhodjaeva, Xoshimov, S. Theoretical bases of hydraulic mixture in round cylindrical pipelines (2020) IOP Conference Series: Earth and Environmental Science, 614 (1). DOI: 10.1088/1755-1315/614/1/012095.

6. G. G. Boeskorov et al., "The Yukagir Bison: The exterior morphology of a complete frozen mummy of the extinct steppe bison, Bison priscus from the early Holocene of northern Yakutia, Russia," Quat. Int., vol. 406, pp. 94-110, Jun. (2016), doi: 10.1016/J.QUAINT.2015.11.084.

7. Y. Wen, S. Shang, K. U. Rahman, Y. Xia, and D. Ren, "A semi-distributed drainage model for monthly drainage water and salinity simulation in a large irrigation district in arid region," Agric. Water Manag., vol. 230, p. 105962, Mar. (2020), doi: 10.1016/J.AGWAT.2019.105962.

8. Z. Hilgendorf, G. Wells, P. H. Larson, J. Millett, and M. Kohout, "From basins to rivers: Understanding the revitalization and significance of top-down drainage integration mechanisms in drainage basin evolution," Geomorphology, vol. 352, p. 107020, Mar. (2020), doi: 10.1016/J.GEOMORPH.2019.107020.

9. T. ElGamal, M. ElFetyany, and G. ElKassar, "Effect of irrigation network rehabilitation on water management-case study: Tanta Navigation canal - Egypt," Alexandria Eng. J., vol. 58, no. 4, pp. 1215-1227, Dec. 2019, doi: 10.1016/J.AEJ.2019.10.005.

10. Aybek Arifjanov, Kudrat Rakhimov, Dilbar Abduraimova, Shamshodbek Akmalov Transportation of river sediments in cylindrical pipeline. XII International Scientific Conference on Agricultural Machinery Industry. IOP Conf. Series: Earth and Environmental Science 403 (2019) 012154.

11. Arifjanov, A., Rakhimov, K., Abduraimova, D., Babaev, A., Melikuziyev, S. Hydrotransport of river sediments in hydroelelators. (2020) IOP Conference Series: Materials Science and Engineering, 869 (7). DOI: 10.1088/1757-899X/869/7/072003.

12. Arifjanov, A., Akmalov, S., Akhmedov, I., Atakulov, D. Evaluation of deformation procedure in waterbed of rivers. (2019) IOP Conference Series: Earth and Environmental Science, 403 (1). DOI: 10.1088/1755-1315/403/1/012155.

13. Arifjanov, A., Samiev, L., Akmalov, S. Dependence of fractional structure of river sediments on chemical composition. (2019) International Journal of Innovative Technology and Exploring Engineering, 9 (1), pp. 2646-2649. DOI: 10.35940/ijitee.L2944.119119.

14. Glukhov D. O., Kremnev A. P., Glukhova T. M. The object-associative approach to the construction of algorithms for calculating and visualizing the space of cylindrical 
sliding surfaces in calculating the stability of slopes, (2011).

15. Muratov, A., Melikuziev, S. Technology of formation of combined products of meliorative purpose (2020) IOP Conference Series: Materials Science and Engineering, 883 (1). DOI: 10.1088/1757-899X/883/1/012060.

16. Arifjanov, A., Otaxonov, M., Samiev, L., Akmalov, S. Hydraulic calculation of horizontal open drainages (2019) E3S Web of Conferences, 97. DOI: 10.1051/e3sconf/20199705039 .

17. Jurík, L', Zeleňáková, M., Kaletová, T., Arifjanov, A. Small water reservoirs: sources of water for irrigation (2019) Handbook of Environmental Chemistry, 69, pp. 115131. DOI: $10.1007 / 698 \_2018 \_301$.

18. Abduraimova, D., Atakulov, D., Ibragimova, Z., Apakhodjaeva, T. Evaluation of erosion and accumulative process with using Geoinformation systems in water resource management (2019) International Conference on Information Science and Communications Technologies: Applications, Trends and Opportunities, ICISCT 2019. DOI: 10.1109/ICISCT47635.2019.9012020.

19. Samiyev, L., Allayorov, D., Atakulov, D., Babajanov, F. The influence of sedimentation reservoir on hydraulic parameters of irrigation channels (2020) IOP Conference Series: Materials Science and Engineering, 883 (1). DOI: 10.1088/1757899X/883/1/012031.

20. Arifjanov, A., Rakhimov, K., Abduraimova, D., Babaev, A., Melikuziyev, S. Hydrotransport of river sediments in hydroelelators, IOP Conference Series: Materials Science and Engineering, 869 (7), (2020) DOI: 10.1088/1757-899X/869/7/072003. 